\title{
Crianças e adolescentes no Brasil: um resgate da trajetória histórica e das políticas públicas voltadas à infância e à adolescência desvalidas
}

\author{
Camila Rose Guadalupe Barcelos Schwonke, M.Sc.*, Adriana Dora da Fonseca, D.Sc.**
}

*Membro do Grupo de Estudos e Pesquisas sobre Enfermagem, Gênero e Sociedadel GEPEGS, Coordenadora do Curso de Enfermagem Faculdades Anhanguera Atlantico Sul Pelotas, **Professora adjunta do Departamento de Enfermagem da FURG, Lider do Grupo de Estudos e Pesquisas sobre Enfermagem, Gênero e Sociedade/GEPEGS

\begin{abstract}
Resumo
A existência de crianças e adolescentes nas ruas em um contexto de abandono e exclusão social é um fenômeno táo antigo que se confunde com a história de nosso país. Neste sentido o presente trabalho consiste em uma reflexão, a partir de um recorte da dissertação de mestrado intitulada "Sexualidade e gênero: a história oral de adolescentes com vivências de rua", do Programa de Pós-graduação em Enfermagem, da Fundação Universidade Federal do Rio Grande, o qual busca discorrer sobre a trajetória histórica de crianças e de adolescentes brasileiras e das políticas públicas voltadas à infância e à adolescência desvalidas. Percebemos ao longo da trajetória histórica que o cenário de violações, injustiças sociais e abandono começa a se delinear ainda no período de colonização do Brasil e que as políticas públicas voltadas a esse grupo social inicialmente apresentavam um caráter muito mais higienista e segregador do que inclusivo.
\end{abstract}

Palavras-chave: políticas públicas, menores de rua, enfermagem, exclusão social.

\section{Abstract}

Children and adolescents in Brazil: recovery of historical and public policy trajectory of defenseless childhood and adolescence

The existence of street children and adolescents in a context of abandonment and social exclusion is an old phenomenon that it is mixed-up with the history of Brazilian country. In this meaning, this study consists of a reflection, based on a master's dissertation titled "Sexuality and gender: oral story of adolescents who have experienced the reality on the streets", of PostGraduation Program in Nursing of Fundação Universidade Federal do Rio Grande, which intends to describe the historical trajectory of Brazilian children and adolescents, and also the public policy related to defenseless children and adolescents. We have noticed, during the historical trajectory, that the scenery of violations, social injustices and abandonment starts in 
the colonization period in Brazil, and that the public policies for this social group showed, initially, a more segregated and hygienist character than inclusive.

Key-words: public policies, street children, nursing, social exclusion.

\section{Resumen}

Niños y adolescentes en Brasil: un rescate de la trayectoria histórica y de las políticas públicas dirigidas a la infancia y adolescencia desvalidas

La existencia de nińos y adolescentes en las calles en un contexto de abandono y exclusión social es un fenómeno tan antiguo que se confunde con la historia de nuestro país. En este sentido el presente trabajo consiste en una reflexión, a partir de un recorte de la disertación de maestría titulada "Sexualidad y género: la historia oral de adolescentes con vivencias de la calle", del Programa de Postgrado en Enfermería, de la Fundação Universidade Federal do Rio Grande, en que se busca discurrir sobre la trayectoria histórica de nińos y adolescentes brasileros y de las políticas públicas dirigidas a la infancia y adolescencia desvalidas. Percibimos a lo largo de la trayectoria histórica que el escenario de violaciones, injusticias sociales y abandono comienza a delinearse desde el periodo de colonización de Brasil y que las políticas públicas dirigidas a ese grupo social, inicialmente presentaban un carácter mucho más higienista y segregador que inclusivo.

Palabras-clave: políticas públicas, menores en situación de calle, enfermería, exclusión social.

\section{Introdução}

A existência de crianças e adolescentes nas ruas em um contexto de abandono e exclusão social é um fenômeno tão antigo que se confunde com a própria história de nosso país. Importamos do continente europeu crianças e adolescentes vitimadas pela exploraçáo de seus corpos, tanto no que se refere à questáo do trabalho árduo e insalubre quanto ao abuso sexual. No entanto, com o decorrer do tempo, de forma lenta e sutil, foram garantidos em lei seus direitos, bem como políticas públicas destinadas a essa população.

Neste sentido as reflexóes que seguem constituem-se em um recorte da dissertação de mestrado intitulada "Sexualidade e gênero: a história oral de adolescentes com vivências de rua" [1], do Programa de Pós-graduação em Enfermagem, da Fundação Universidade Federal do Rio Grande e buscam discorrer sobre a trajetória histórica de crianças e adolescentes no Brasil e das políticas públicas voltadas à infância e à adolescência desvalidas.

Identificamos como sendo necessário dividirmos a construção deste texto em dois pilares: o primeiro refere-se ao resgate histórico, ou seja, da maneira como se construiu a história de crianças e adolescentes no Brasil, tendo como foco principal os cuidados de saúde dispensados a este grupo social em diferentes momentos da história, com ênfase especial as questôes referentes ao abandono. $\mathrm{O}$ segundo bus- ca discutir a evolução das políticas públicas voltadas à infância e à adolescência desvalidas, inicialmente construídas com ênfase no assistencialismo e na filantropia, até a elaboração e efetivação do Estatuto da Criança e do Adolescente (ECA).

\section{Crianças e adolescentes do Brasil colônia ao Brasil contemporâneo}

A história de desrespeito, violência sexual, maus-tratos, trabalho infantil, fome e miséria na infância e adolescência no Brasil, iniciou nas caravelas portuguesas, que desbravando as águas oceânicas, trouxeram, no seu interior, crianças e adolescentes que, juntamente com adultos, colonizaram o país. As crianças e adolescentes, nas embarcaçóes lusitanas do século XVI, subiam a bordo na condição de pagens, grumetes, órfấs do Rei enviadas ao Brasil para casarem com os súditos da Coroa, ou como passageiras/os em companhia de pais ou parentes [2].

Independentemente da condição em que estes miúdos se encontravam, eles eram quem mais sofriam com as grandes aventuras marítimas. Os grumetes e os pagens eram vítimas de abusos sexuais de marujos violentos; nem mesmo as crianças acompanhadas dos pais livravam-se da ação de pedófilos; e as órfấs do rei tinham de ser protegidas e vigiadas a fim de se manterem virgens até que chegassem à colônia [2]. 
Para os portugueses, as crianças eram consideradas pouco mais do que animais, cuja força de trabalho deveria ser aproveitada até que sua vida fosse exaurida, sendo que sua expectativa de vida girava em torno de 14 anos entre os séculos XIV e XVIII [2].

No Brasil, em períodos anteriores a colonização, os índios, habitantes nativos, possuíam uma expectativa de vida em torno de 120 anos e um baixo índice de mortalidade infantil entre eles. Ao penetrarem na nova colônia, os portugueses não trouxeram apenas mudanças no padráo cultural, com a introdução de novos costumes, mas também diversos microrganismos e doenças estranhas a esse meio, destacando-se a varíola que causou danos irreparáveis a vida [3].

A ação dominante portuguesa sobre o povo nativo da nova colônia iniciou-se mais incisivamente a partir de 1549, quando desembarcaram aqui os jesuítas liderados pelo Padre Manoel da Nóbrega, que com outros padres compunham a "Companhia de Jesus”. O objetivo desta Companhia era a evangelização das crianças indígenas, que eram vistas como "um papel branco, a cera virgem, em que se tanto desejava escrever-se e inscrever-se" [4:58].

O século XVIII foi marcado pelo descaso com o cotidiano da infância, em especial a forma como viviam crianças escravas e pobres. Nas senzalas, onde habitavam escravas/os de um mesmo proprietário, era comum ver crianças freqüentando todos os lugares, inclusive as habitaçóes dos senhores, convivendo com seus filhos e relacionando-se com suas donas [5].

A Lei do Ventre Livre, em 1871, tornou libertos os filhos das escravas, que passaram a ser criados pelos seus senhores [3].

$\mathrm{O}$ nascimento de uma criança negra era a certeza da existência de uma ama-de-leite capaz de amamentar as/os filhas/os dos senhores, em detrimento da sobrevivência do filho dessa escrava, que não tinha nenhum valor para a burguesia. Como o aleitamento era visto com bons olhos pela igreja, as escravas que davam à luz eram até mesmo alugadas para amamentar crianças nobres [5].

As primeiras formas de abandono surgem ainda nesse período, quando os senhores, querendo fazer uso de suas escravas cativas como amas-de-leite, abandonavam os filhos das mesmas. Ademais, para a burguesia, as crianças negras só começavam a trazer lucro na faixa de sete, oito anos, quando iniciavam a trabalhar como mensageiros, carregadores de en- comendas, entre outras atividades, o que fomentava a prática do abandono, pois representava prejuízos financeiros aos senhores [3].

O século XVIII ainda foi marcado por uma preocupação maior por parte da Medicina, no que se refere aos aspectos relacionados à saúde de crianças e adolescentes. A alimentação na primeira infância ganha ênfase, fazendo com que médicos estrangeiros dirigissem duras críticas à forma como as escravas alimentavam as crianças brancas: "com mingau de tapioca que elas lhes levavam à boca servindo-se para isso dos dedos". Assim, introduziam-se alimentos indigestos como cevadas, farinha e feijão cozido, com a idéia de engordar as crianças, dar-lhes o que comer [6:88].

As doenças da infância e adolescência, nos meados do referido século, eram associadas a açôes de bruxas, de quem as amas deviam defender essas crianças, sendo as doenças mais comuns "o mal dos sete dias", a sarna, a erisipela e a "bexiga". A mortalidade infantil foi abrandada, porém ainda gerava inquietações nos higienistas do século XIX [6:91].

Acariciar os filhos, contar-lhes histórias, aproximar-se com ternura e iniciar sua alfabetização eram consideradas atitudes exclusivamente femininas, fortalecendo-se, nessa época, o vínculo mãe/filho [6], o que, a partir de uma perspectiva de gênero, pode explicar as cobranças e responsabilidades delegadas à mulher em ser a mantenedora de afeto e educação dos filhos, ainda observadas nos dias de hoje, mesmo que seja efetiva a participação paterna.

Porém, nesse período, as violências dirigidas às mães atingiam também suas/seus filhas/os. Não foram poucas as famílias que entregaram mães e filhas/ os à própria sorte, de modo que a fome, $\mathrm{o}$ abandono, a instabilidade econômica e social ficaram impressas em muitas crianças que se encontravam esmolando nas portas das igrejas junto com suas mães [6].

Dessa forma, durante os séculos XVIII e XIX, foram criadas várias "Casas dos Expostos", junto às Santas Casas de Misericórdia [7]. Estas casas tinham por objetivo acolher crianças abandonadas, até completarem sete anos de idade. Assim, as/os filhas/os fora do casamento e a situação de pobreza das famílias fizeram aumentar o número de crianças abandonadas no país, fazendo surgir, em 1726, na Bahia, a "Roda dos Expostos".

No Rio Grande do Sul foram criadas três rodas de expostos com o mesmo espírito filantrópico: a de Porto Alegre, em 1837; a da cidade do Rio Grande, em 1838; e a de Pelotas, em 1849 [8]. 
De modelo europeu, a roda consistia em um equipamento cilíndrico onde se colocava a criança abandonada que seria recebida por outra pessoa no lado oposto, sem que ambos pudessem se enxergar, ou seja, quem a abandonava e quem a recebia. Essas crianças podiam permanecer no local no máximo até os sete anos de idade, sendo, depois, encaminhadas para outras instituiçóes que atendiam a órfãos ou para uma família, ficando a decisão a cargo de um juiz [9].

"O século XIX ratifica a descoberta humanista da especificidade da infância e da adolescência como idades da vida", sendo que em 1830 os termos "adolescente e menino" aparecem em dicionário, e o "menina" diz respeito a tratamento carinhoso e só mais tarde passa a designar "criança ou pessoa do sexo feminino que está no período da meninice" [10:140].

As crianças de elite, devido ao limitado saber médico e ausência de vacinação regular, estavam suscetíveis a doenças variadas, tendo sido intensificado na época o incentivo à amamentação e aos cuidados de saúde como: anti-sepsia do cordão umbilical, o uso de vestimentas limpas e adequadas, verificação da temperatura da água do banho, entre outros [10].

Com o advento da República, que culmina com o processo de expansão e urbanização do país, no século $\mathrm{XX}$, vem à tona a problemática social acerca dos meninos de rua, nas grandes cidades brasileiras, originando as primeiras obras voltadas à infância desvalida [11].

A República traz consigo a esperança de um regime democrático que proporcionasse garantias aos seus cidadáos. Era o nascimento de novos tempos, nos quais o Brasil poderia ser igualado a grandes naçóes [12]. Porém, esse foi um período em que crianças e jovens experimentaram crueldades inimagináveis, produzidas na própria família, na escola, nas fábricas, nos confrontos entre gangues, nos internatos, nas ruas e entre marginais e policiais. As dificuldades vivenciadas levaram os pais a abandonarem cada vez mais seus/suas filhas/os. Tal realidade ocasionou uma nova ordem de assistência a esse grupo, ultrapassando o nível da filantropia privada com seus orfanatos para tornar-se um problema do Estado, que exigia políticas sociais e legislação específica [12].

A industrialização, a urbanização e a crescente pauperização no século XX trazem à tona as ameaças que o número cada vez maior de adolescentes, iniciados/as na prática da vadiagem e "gatunagem", traziam às cidades [13:214].

Nesse período da república surgem e agravamse as crises sociais, permeadas pelo aumento da criminalidade que fez com que muitos criminalistas buscassem a origem da delinqüência na infância [13].

A ação de meninas/os nas ruas das cidades, em bandos ou sozinhas/os, passa a compor o quadro e as estatísticas de criminalidade e de delinqüência. Era comum esses sujeitos transitarem entre atitudes lícitas e ilícitas, servindo de mão-de-obra em pequenos serviços e na sua ociosidade passarem a praticar furtos. Esse fato forçou a revisão do Código Penal da República, que passou a considerar puniçóes a infratores entre nove e quatorze anos, que agiam conscientemente e eram recolhidos para instituiçóes disciplinadoras, inaugurando assim as políticas públicas voltadas à infância e à adolescência desvalidas como passaremos a ver a seguir.

\section{As políticas públicas para crianças e adolescentes no Brasil: o caminho percorrido até o ECA}

As açóes voltadas para a infância desvalida no Brasil surgiram entre os séculos XVIII e XIX, com ações filantrópicas, beneficentes e religiosas, nas Santas Casas de Misericórdias, através da Roda dos Expostos, isentando o Estado de assumir qualquer responsabilidade com os cuidados e a tutela de crianças abandonadas.

É a partir do período republicano que surgem diversos dispositivos jurídicos e órgãos governamentais, com enfoque na questáo da infância e adolescência desvalida, que passa, então, a ser tratada como prioridades nas políticas públicas, fazendo surgir, em 1901, o Instituto de Proteção e Assistência à Infância no Rio de Janeiro, órgão que serviu de modelo para a criação de outros dispositivos legais como o Juizado de Menores, em 1923, e o primeiro Código de Menores, em 1927 [14].

Com o advento da república, no século XX, instala-se um período de instabilidade econômica e social, no qual, as pessoas que moravam na periferia, em precárias condiçóes, principalmente de habitação, passaram a ser alvos do atendimento social [12]. Essas pessoas eram vistas regularmente trocando de parceiros, compondo famílias numerosas, apresentando, assim, carências culturais, psíquicas, sociais e econômicas, o que as incitava à criminalidade e, mais tarde, à delinqüência. Como conseqüência desse 
contexto, seus filhos eram geralmente desnutridos e com pouca ou nenhuma escolaridade. Cresciam, na maioria das vezes, privados da presença do pai, da mãe, ou de ambos [12].

Observava-se, nesse período, uma grande ênfase na família "desestruturada" como a geradora de criminosos comuns e de ativistas políticos. As pessoas oriundas dessas famílias eram vistas como criminosas, fazendo com que o Estado passasse a assumir as tarefas de educação, saúde e punição para crianças e adolescentes, de forma que toda política formulada para integrar tais indivíduos carentes buscava diminuir a delinqüência e a criminalidade [12].

Dessa forma o conceito de menoridade no Brasil começou a ser empregado durante a Primeira República e que não se encontrava vinculado às questóes etárias, mas sim, associado ao conceito de marginalidade, em situaçóes de abandono ou delito, sendo presságio de criminalidade, devendo, portanto, ser tratado como caso de polícia [15].

Nessa perspectiva, na década de 1920, instalavam-se açóes governamentais que buscavam afastar as crianças das ruas, através de seu recolhimento para instituiçóes públicas, as quais deveriam aplicar medidas preventivas e corretivas. Assim, com essa ótica, inaugurou-se, em 1927, o Primeiro Código de Menores que: "consolida legalmente esta prática de prevenção ligada ao ideário de periculosidade" [15:76].

O Código de Menores de 1927 regulamentou o trabalho infantil, até que este passou a ser proibido para menores de 14 anos, sem permissáo Judicial, a partir da Constituição de 1934. Porém, o Estado já esboçava açôes anteriores ao Código de 1927, quando, em 1891, através do Decreto no. 13.113, proibia o trabalho de crianças em máquinas em movimento e em faxina, e, mais tarde, em 1923, pelo decreto 16.272 regulamentava a proteção aos menores abandonados e delinqüentes, concebendo a situação de pobreza como geradora de crianças abandonadas e de jovens delinqüentes [12].

A década de 1920 é então marcada pelas primeiras experiências de institucionalização e internação de "menores" em entidades oficiais. Volta-se também o olhar, naquela época, para o trabalho realizado por menores de rua. A formulaçáo do primeiro Código de Menores buscou classificar em "delinqüentes e abandonados" as crianças e adolescentes com idade inferior a 18 anos, introduzindo a categoria "menor", que até o fim dos anos 70 é utilizada com poucas alteraçóes [11].
As décadas subseqüentes foram permeadas por outras intervençóes governamentais nessa área. Nesse sentido, em 1940, o Departamento Nacional da Criança e do Serviço de Assistência ao Menor (SAM) buscava a recuperação de menores infratores por meio da internação. Esse órgão foi substituído, durante o regime militar, pela Fundação Nacional de Bem-Estar do Menor (Funabem), que surgiu com a intenção de frear a "lógica carcerária" do SAM, mas que acabou por reproduzir o seu modelo de encarceramento [11].

Com a extinção do SAM, que objetivava sistematizar os serviços de atendimento aos menores delinqüentes internados, a Funabem surge com o objetivo de formular e implantar, em cada estado, a Política Nacional do Bem Estar do Menor, que deveria se integrar a programas nacionais de desenvolvimento econômico e social, enfatizando as necessidades afetivas, nutritivas, sanitárias e educacionais dos institucionalizados [12].

$\mathrm{Na}$ verdade, ao institucionalizar seus "menores infratores", ou não, o Estado buscava "educar pelo medo" e, também, recolher da sociedade os filhos da pobreza, os quais, pela sua simples presença, eram associados à marginalidade e à delinqüência, pois fugiam aos padrôes de organização social esperados.

Nessa perspectiva, a terminologia "menor", largamente difundida na década de 1950, buscava designar jovens infratores ou abandonados, oriundos das situações de pobreza, expandindo-se, assim, o complexo institucional de controle para os inimputáveis, que objetivava o atendimento para menores de idade, pobres e perigosos [12].

A transição do termo "menor" para a adoção de expressóes como crianças e adolescentes, ocorreu a partir de 1979, com a formulação do novo Código de Menores [14]. Esse código legitimava uma nova concepção de menor abandonado, pobre, infrator e/ou delinqüente, pela utilização - que, sob nossa avaliação é mais branda - da terminologia "situação irregular”. No entanto, essa nova expressão concebida no berço da ditadura militar, ao invés de amenizar acabou por fortalecer as idéias preconizadas anteriormente, em particular a "figura do delinqüente", ou seja, do indivíduo "perigoso", o qual era tido como fruto da associaçáo da pobreza com a marginalidade, de quem a sociedade e o Estado deveriam se defender [15].

Dessa forma, a utilização do termo "situação irregular" estabelecia um padrão de normalidade, devendo-se recolher todos aqueles que dele se dis- 
tanciassem. Assim, o novo código foi alvo de várias críticas, fomentando, nos movimentos sociais de defesa e direitos da criança e do adolescente, um novo perfil social que deveria compor uma nova legislação [15].

Observamos que, até o presente momento da história das políticas públicas voltadas para a infância e para a adolescência abandonadas, associava-se pobreza a marginalidade, abandono a delinqüência, tendo, estas práticas, portanto, um perfil "reformador" e segregador, capaz de identificar as mazelas da sociedade. O objetivo maior era institucionalizar para higienizar e educar, porém, dificilmente, devolvia-se a ela um ser humano capaz de transformar o futuro que lhe fora imposto por uma vida de privaçóes e pobreza.

Os anos 80 foram marcados pelo surgimento de um número expressivo de Organizaçóes NãoGovernamentais (ONGs), as quais eram especializadas em açóes públicas, estudos e denúncias acerca do fenômeno social dos meninos de rua, que na época eram o símbolo da pobreza, da desigualdade social, da violência e do descaso das autoridades brasileiras [11].

Entre as ONGs surgidas nessa época, merece destaque o Movimento Nacional dos Meninos e Meninas de Rua (MNMMR), ainda hoje extremamente atuante e com forte representatividade na formulação de políticas voltadas a este grupo social.

O MNMMR surgiu em 1985, congregando militantes e profissionais de projetos de educação social, mobilizados em modificar a legislação vigente. Diferentemente de outras ONGs, o movimento busca mobilizar meninos (de rua ou não), em defesa de seus próprios direitos, através da participação em núcleos regionais e em encontros nacionais, que desde 1986, ocorrem em Brasília e que servem como um fórum de denúncias sobre violência, assassinatos e maus-tratos contra crianças e adolescentes [11].

Esses segmentos organizados da sociedade forçaram a revisão do Código de Menores de 1979, o que ocorreu durante o processo de abertura política no regime militar. Em 1988, com a nova Constituição, houve o rompimento da díade pobrezadelinqüência, podendo, então, ser pensado em um novo código, o qual foi denominado de Estatuto da Criança e do Adolescente - ECA [12].

O ECA [16], sancionado pela Lei $n^{\circ} .8069 / 90$, é uma conquista de toda esta mobilização social, mas, principalmente, configura-se em um marco na maneira de perceber a criança e o adolescente e de responsabilizar o Estado, que agora modifica suas ações de reclusão, encarceramento e punições, para aquelas voltadas ao acolhimento, garantias de direitos e resgate da cidadania.

As diretrizes preconizadas pelo ECA redirecionam a atenção a saúde da criança e do adolescente no país, pois levam em consideração "a humanização dos procedimentos, a capacitação dos agentes, a modernização das estratégias, a maior alocação dos recursos, a compreensão da infância e da adolescência como momentos singulares no desenvolvimento destes sujeitos e a proteçâa integral necessária à construção da cidadania" [3].

Assim, o reconhecimento dos "menores" como crianças e adolescentes, que possuem direitos e responsabilidades, acontece com o ECA, segundo o qual eles passam a ser compreendidos como cidadãos, pessoas em uma fase singular e importante de seu desenvolvimento. A partir de entáo, esta parcela significativa da populaçáo brasileira começa a ser tratada como prioridade absoluta, sendo de responsabilidade do Estado e da sociedade a garantia de aplicação desta Lei [14].

Torna-se importante ressaltar que o ECA, em seu artigo $4^{\circ}$, elenca os deveres da família, da sociedade e do poder público com suas crianças e adolescentes, fazendo referências ao direito, entre outros, à saúde, reforçando, assim, a relevância de trabalhos como estes que apresentam como objeto de estudo a saúde de adolescentes com vivências de rua. Diz a lei: "é dever da família, da comunidade, da sociedade em geral e do Poder Público assegurar, com absoluta prioridade, a efetivação dos direitos referentes à vida, à saúde, à alimentação, à educação, ao esporte, ao lazer, à profissionalizaçáo, à cultura, à dignidade, ao respeito, à liberdade e a convivência familiar e comunitária" [16:23].

Desse modo percebemos que, teoricamente, o ECA modificou a maneira, tanto do Estado, quanto da sociedade, de ver os seus herdeiros desvalidos, porém são observadas ainda, na prática, violaçôes a este estatuto, na medida em que cresce o número de adolescentes com vivências de rua, e que fazem dela o espaço para a manutenção da sua sobrevivência através do trabalho braçal, na maioria das vezes insalubre, bem como de roubos e prostituição. Assim, tornam-se vítimas da violência física e psicológica que os afasta cada vez mais de espaços socializadores, como a escola e a família.

Nesse sentido a enfermagem precisa atuar de forma mais intensa, não só na condição de profis- 
sional, mas principalmente como cidadáo, o enfermeiro deverá, sempre que possível, fazer cumprir os direitos dos jovens previstos no ECA, articulando-se para isso com diversos segmentos sociais e pautando suas açóes tendo-o como referencial norteador.

O envolvimento do enfermeiro com movimentos populares e organizaçóes não-governamentais revela seu papel social não só como uma atribuição profissional, mas principalmente como cidadão na luta da construçáo de uma sociedade mais igualitária e equânime [17].

\section{Conclusão}

Percebemos, por intermédio destas passagens históricas que é ainda no período colonial que se desenha o início da construção do cenário de violaçóes, injustiça social e abandono que é observado ainda nos dias atuais, mais de quinhentos anos após a chegada dos portugueses ao Brasil. Afinal, o que esperar de uma nação que é colonizada utilizando o árduo trabalho de crianças e adolescentes? E como se não bastasse, constrói suas relaçóes com esses sujeitos pautadas no desrespeito, refletido por meio da violência sexual e das violaçóes de direitos.

Considerando esses registros históricos, observamos que quem mais sofreu foram aquelas crianças e adolescentes advindos de famílias pobres ou que se encontravam em situaçóes de abandono. Eram submetidos ao árduo trabalho infantil, às péssimas condiçóes de vida e à prostituição, como atualmente acontece com estes sujeitos que são provenientes de camadas sociais menos favorecidas, como no caso dos atores sociais de interesse deste estudo.

A ação de pedófilos, a chacina praticada em crianças faveladas, a prostituição de menores e a imersão no mundo cruel das drogas são notícias corriqueiras na mídia, nas últimas décadas, além, é claro, das cenas observadas no cotidiano, como as de mendicância ou roubo que estes jovens realizam a pessoas nas ruas das cidades de todo o país.

A construção de políticas públicas que pudessem interferir nesse cenário, ao longo da história, demonstrou ter um caráter muito mais segregador e higienista do que realmente de inclusão dessas crianças e adolescentes em um contexto socializador.

O ECA apresenta-se como um marco importante na garantia de direitos, desses atores sociais, porém a sua efetivação enquanto política pública está longe de ser a ideal e necessita, para tanto, da articulação dos diversos setores da sociedade e do engajamento de profissionais das diversas áreas, principalmente do enfermeiro.

Portanto, resgatar a história das crianças e adolescentes brasileiros e do contexto das políticas públicas vivenciadas pelos mesmos obriga-nos, infelizmente, a resgatar um passado de dor, diferenças e injustiças sociais, racismo, autoritarismo e desrespeito que, mesmo sendo ainda reproduzidos em pleno século XXI, deveriam servir de mola propulsora na construção de um presente-futuro digno a esses atores sociais.

\section{Referências}

1. Schwonke CRGB. Sexualidade e gênero: a história oral de adolescentes com vivências de rua [dissertação]. Rio Grande: Programa de Pós-graduação em Enfermagem. Fundação Universidade Federal do Rio Grande; 2006.

2. Ramos FP. A história trágico-marítima das crianças nas embarcaçóes portuguesas do século XVI. In: Del Priore M, ed. História das crianças no Brasil. 4a. ed. São Paulo: Contexto; 2004. p.19-54.

3. Santana JSS. O processo de exclusão de adolescentes no Brasil: sua origem na infância desvalorizada. In. Ramos FR et al., Eds. Adolescer: compreender, apoiar, acolher. Projeto Acolher: Um encontro da enfermagem com o adolescente brasileiro. Brasília. ABEn/Governo Federal; 2000. 195p.

4. Chambouleyron R. Jesuítas e as crianças no Brasil quinhentista. In: Del Priore M, ed. História das crianças no Brasil. 4a ed. São Paulo: Contexto; 2004. p.55-83.

5. Scarano J. Criança esquecida das Minas Gerais. In: Del Priore M, ed. História das Crianças no Brasil. 4a ed. Sáo Paulo: Contexto; 2004. p.107-136.

6. Del Priore. M. O cotidiano da criança livre no Brasil entre a colônia e o Império. In: Del Priore M, ed. História das crianças no Brasil. 4a ed. São Paulo: Contexto; 2004. p.84-106.

7. De Camargo CL, Alves ES, Quirino MD. Violência contra crianças adolescentes negros: uma abordagem histórica. Texto \& Contexto Enferm 2005;14(4):60815.

8. Gomes VLO. A interpretação do cuidado de enfermagem à criança em creches, pela ótica de Pierre Bourdieu [tese]. Florianópolis (SC): Programa de Pós-Graduação em Enfermagem/ UFSC; 2004. 177p.

9. Venancio RP. Os aprendizes da guerra. In: Del Priore M, ed. História das crianças no Brasil. 4 a ed. São Paulo: Contexto; 2004. p. 178-192.

10. Mauad AM. A vida das crianças de elite durante o império. In: Del Priore M, ed. História das crianças no Brasil. 4a ed. São Paulo: Contexto; 2004. p.108-137.

11. Gregori MF. Meninos de rua e instituiçóes, tramas, disputas e desmanche. São Paulo: Contexto; 2000.

12. Passetti E. Crianças carentes e políticas públicas. In: Del Priore M, ed. História das crianças no Brasil. $4^{\mathrm{a}}$ ed. São Paulo: Contexto; 2004. p.318-347. 
13. Santos MAC. Criança e criminalidade no início do século. In: Del Priore M, ed. História das crianças no Brasil. 4a ed. São Paulo: Contexto; 2004. p.193-210.

14. Schwonke AA. A rua vai à escola? Papel da escola para adolescentes em situação de rua na cidade de Pelotas/ RS [dissertação]. Pelotas: Faculdade de Educação/ UFPel. 2001.

15. Oliveira MS. A moral reformadora e a fusão de mentalidades adolescente sob o discurso penalisador. São Paulo Perspec 1999;13(4).
16. Brasil. Lei n.8069 - 13 de julho 1990. Dispóe sobre o Estatuto da Criança e do Adolescente, e dá outras providências. 42a Ed. São Paulo: Código Civil; 1992.

17. Oliveira AAP, Ribeiro MO O cuidar da criança de/na rua na perspectiva dos graduandos de enfermagem. Texto \& Contexto Enferm 2006;15(2):246-53. 